\title{
Contention over growth promoters
}

Unwelcome technical findings can cause ructions when they are made public, for which reason the technical community has a responsibility to its findings to argue its case in advance with their opponents.

Brussels. Suppose you hold a conference on a contentious subject and seek to persuade the world that whatever conclusion you reach, it should be taken seriously. There are several stratagems that can be followed. One is to alert the press and television people to what is afoot, in the hope that they will amplify the message. Another is to print the message on glossy paper and distribute that to the people called opinionformers. The trouble is that neither method can be guaranteed success. Journalists may choose to look the other way, or may be forced to do so by unexpected events, while the great and the good may have other things on their minds.

That may be part of the reason why Dr Franz Fischler, agriculture commissioner at the European Commission, asked that last week's conference on growth promoters in meat production should be attended not only by 85 or so scientists in the field but also by nearly twice as many people with a secular interest in the subject - members of the European Parliament, of the European Council's Economic and Social Committee and representatives of pressure groups that legitimately attempt to lobby the European Commission on consumer issues and related matters.

The outcome would have been amusing had it not also been depressing. Is it no longer possible for there to be a public statement of an inference based on an examination of existing data without exciting the complaint that the scientific profession has risen above itself, seeking to force ill-formed opinions down other people's throats?

On this occasion, the inferences were not all that remarkable, anyway. The underlying question is whether farmers should be allowed to use substances that promote the growth of livestock, and if so, under what conditions (see Nature 377, 381; 1995). The issue has been alive since 1988 , when the European Community (as it then was) restricted the use of anabolic agents in animal husbandry. Many farmers grumbled and some took to the illicit use of, for example, anabolic steroids such as testosterone.

The big change since 1988 is that there is now a whole battery of growth-promoting agents on, or just over, the horizon. That is not surprising. Apart from antibiotics (which reduce the metabolic load of microflora in an animal's gut) and preparations of natural reproductive hormones and their relatives (sometimes synthetic) of the kind illicitly used by athletes to enhance muscle-power, there is a family of synthetic chemicals called $\beta$-agonists, essentially analogues of adrenaline. They appear to have been first used in the treatment of horses suffering from chronic pneumonia, as adrenaline itself is sometimes used in people; increased growth appears to have been observed adventitiously.

But that is only the beginning of a lengthening list. Why not use growth hormones proper, perhaps bioengineered, to make animals grow more quickly, or materials such as somatotrophin, which may or may not (according to circumstances) have similar effects? There is even talk of suppressing the effects of metabolic enzymes by means of antibodies, or of adjusting the periodic exposure of animals to light, which may (but may not) affect growth through the intermediary of melatonin. And there is always, of course, gene transplantation.

Which, if any, of these routes can be safely used to promote the growth of farm animals? That cannot be a simple question, but entails an exercise in risk analysis. First, the hazards (in the sense of potential damage to the health of the animals themselves and of people who eat the meat) must be identified by the standard process of imaginative scepticism. Are children, or pregnant women, especially prone to damage? Can oestrogens added to the environment cause long-term reproductive damage? And then it is necessary to search the literature for evidence for some numerical link between the doses of these materials likely to be administered to animals or unwittingly ingested by people and the risk that individuals will be damaged. That textbook statement is impeccable; the difficulties arise in dealing with particular cases.

What last week's conference decided is that there is now no reason to suppose that the use of the reproductive steroid hormones, sanctioned for more than 30 years in the United States, Canada, Australia and New Zealand, is damaging to meat-eating consumers, although there may still be room for doubt about the effects of these materials on the animals to which they are administered, notably in the possibility that they may affect behaviour.

But the $\beta_{2}$-agonists are in a different case. There has been a handful of incidents in the past few years in which numbers of people have been acutely injured by eating liver from animals treated with them. And there is too little information about the functioning of apparently simple hormones such as growth hormone for a judgement to be made (although bovine growth hormone is sanctioned for use in Australia).

Thus stated, these findings seem innocuous enough, but the first, as everybody was well aware, fails to justify the restrictions placed on the use of steroid hormones by the European Union (EU) in the late 1980s. But the participants were also aware (they were reminded of that often enough) that decisions about the regulation of substances in the food chain may properly involve political, economic and even idiosyncratic considerations - people may prefer not to eat residues of chemicals not naturally present and, if they are in a majority, may carry the day. So the two findings were presented as strictly technical findings, not in themselves a sufficient basis for changing EU policy on steroid hormones as growth promoters.

And then the skies fell in. One speaker complained that the pretence that it possible to consider technical issues in isolation from broader issues is an abnegation of social responsibility and was the reason why Frankenstein (but he may have meant Hitler) was able to flourish. Another held that a bunch of scientists had no business telling the larger community how to conduct its affairs. The question of "Why are we talking about this issue when Europe has too much meat?" arose in several forms, and apparently in oblivion of threats by the United States that it will use international trading mechanisms (now the World Trade Organization) to win compensation for its beef-producers on account of the EU policy. Another refrain was that opinion polls have shown that EU meat-eaters prefer their beef without added growth promoters.

The depressing feature of the proceedings is the huge gulf that appeared between the technical people and the politicians; the two groups seemed to be talking about different topics. So was it a mistake to mix two such disparate groups together? The truth is the opposite; if the gulf is so wide, surely it is in the public interest that there should be more talk, not less. But is not that a waste of time? It is only necessary to imagine that the subject had been something really serious, like the use of nuclear weapons, to know that the answer must be "No!". But steroids in meat is also an important issue. The man who mentioned Frankenstein was wrong in what he said, but he might not have spoken as he did if technical people had talked to him more often. That is the lesson.

John Maddox 